\title{
Police Reform: Understanding Interspersed Social Influences and the Propagation of Public Policy During COVID19
}

\author{
Alexia L. Knox \\ Marquette University Graduate School of Management \\ Diederich College of Communication, Alumni \\ 1131 West Wisconsin Avenue, Milwaukee, Wisconsin 53233, USA
}

\begin{abstract}
Social influence is described as a communications theory which involves three psychological processes: compliance, identification and internalization. The theory applies supplemental data from social psychology frameworks consisting of normative conformity and informative conformity research. Individuals can be influenced to demonstrate social behaviors and many of us can be influenced to change our behaviors depending on our psychological or social needs at that time. Propaganda is another social influence that affects crisis communications. These topics will be discussed to better understand social influence and social behaviors while also analyzing legitimate authority interpositions during the coronavirus global crisis. Further, this research task will examine observational research data, compare antecedent events that prompted these discussions, to support a theoretic approach that consists of organizing ontological perspectives to adduce an analysis of understanding intervals of interspersed social influences resulting in the propagation of public policy, particularly, police reform.
\end{abstract}

Keywords - Interspersed social influence, propaganda, police reform, crisis communications, COVID-19

SUGGESTED CITATION: Knox, A. L. (2021). Police reform: Understanding interspersed social influences and the propagation of public policy during COVID-19. Proceedings of the International Crisis and Risk Communication Conference, Volume 4 (pp. 68-71). Orlando Fl: Nicholson School of Communication and Media. https://doi.org/10.30658/icrcc. 2021.17

\section{INTRODUCTION}

The study of social influence in psychology provides the framework of how human beings possess a psychological need to be correct or liked by others. The psychological need to be liked is the most common prerequisite of social influence. Our need to be liked by others is referred to as normative conformity, a social influence that proposes that people conform their behaviors and beliefs based on a desire to be accepted by others over a short period of time. Informative conformity is defined as our need to be correct, which is influenced by information provided by others and accepted as evidence which changes our behaviors and beliefs over a long period of time. The complexities of compliance, identification and internalization psychologial processes prompts four social influences: conformity, obedience, compliance and propaganda. Most people can be influenced to change behaviors or beliefs depending on psychological processes, social influences and psychological or social needs. A legitimate authority, such as a police department, might parallel social influence during the coronavirus pandemic, propagating social change.

\section{LITERAURE REVIEW}

In the field of communications, social influence is a theory identified by Harvard University psychologist, Herbert Kelman, which involves social influence processes: compliance, identification and internalization. These three processes are applied theoretically to better understand human behaviors, beliefs and attitude changes in social environments. Compliance occurs when an individual accepts influence because he or she hopes to achieve a favorable reaction from others; identification occurs when an individual accepts influence because he wants to establish or maintain a satisfying self-defining relationship to another person or group; internatization occurs when an individual accepts influence because 
the effect of such behavior is intrisically rewarding. The complexities of compliance, identification and internalization processes diverges into a prevailing social order of social norms consisting of public behaviors induced by four social influences: conformity, obedience, compliance and propaganda. Conformity involves a change in belief or behavior in order to fit in with a group; obedience requires an individual to act in response to a direct order from another individual, who is usually an authority figure; and compliance occurs when an individual does what someone else wants them to do following a request or suggestion. Propaganda is generally defined as, "Communication designed to manipulate a target population by affecting its beliefs, attitudes, or preferences in order to obtain behaviour compliant with political goals of the propagandist'"[2].

Trending behaviors in social environments demonstrate the presence of social influence that veer towards normative conformity and establishes an awareness of societal standards regarding what is acceptable in social environments. After the initial outbreak of the coronavirus pandemic, governments within the U.S. and countries like China, issued orders governing social interactions and proximity to reduce the spread of the coronavirus. German sociologist, Max Weber describes an order as a system consisting of rules that orient behaviors. Orders in the U.S. and China consisted of requiring the use of face masks in social spaces, increasing space between individuals by at least 6 feet and selfquarantining. In addition to orders and public obedience to those orders, proxemics and social space concepts influence social behaviors as well. Anthropologist, Edward T. Hall, coined the term, 'proxemics' and suggested dividing human use of space into four zones, including a "Social Space," ranging from 4 feet to 12 feet, which would require individuals to behave differently. Moreover, social behaviors that are ordered by a bureaucratic authority or government, such as, a government requiring individuals and groups to social distance, demonstrate an enforcement of social behaviors based on proximity.

\section{METHODS}

The following qualitative research has been conducted to support a theoretic approach in understanding social influences and the propagation of public policy, particularly, police reform during the coronavirus global crisis to include ontonolgical perspectives of observational data and antecedent events.

Observational Data: There is a growing distrust of government or authority amongst individuals and groups, particularly, during the coronavirus global pandemic. In 2019, prior to the coronavirus pandemic, three-quarters of Americans say that their fellow citizens' trust in the federal government was shrinking [6]. Months after the outbreak, $20 \%$ of Americans trusted the federal government [7]. The United States continued to suffer an economic recession due to the coronavirus pandemic and lawmakers were not successful at reaching an agreement for a second stimulus bill. Just $20 \%$ of U.S. adults say they trust the government in Washington to "do the right thing" just about always or most of the time [7]. Many Americans assessed blame onto the federal government for the economic recession due to the coronavirus pandemic. Forty percent of respondents to a survey blamed Democrats, $39 \%$ held former former President Donald Trump Republicans most responsible and another $18 \%$ said they blame both parties equally [8]. Ongoing reports and breaking news about the coronavirus crisis created panic and stress. The World Health Organization explains that the coronavirus pandemic crisis generates stress throughout the population [10]. Also, information shared on social media during the pandemic has been mostly unreliable and has contributed to the distrust of the U.S. governmemt and panic. Nearly 7 out of 10 U.S. adults say fabricated news and information greatly affect Americans' confidence in government institutions [3]. Further, a plethora of disinformation about elections was shared via social media and the dissemination of images and videos intended to produce an "us against them" reaction to mobilize viewers, readers and listeners to political action during a "fake news" era increased public distrust of the government which forged propaganda against the government via protests, riots, police violence and policy, such as the urgent demand for police reform a month prior to the coronavirus international outbreak [2].

Antecedent Events: The publicized death of George Floyd, a black man killed by white Minneapolis police officer, Derek Chauvin, during the pandemic, affected public trust of the government. According to an article, "For two decades, federal officials repeatedly recommended reforms to increase accountability, curb use-of-force violations and build up community trust, according to more than half a dozen government reports" [1]. The injustice against George Floyd by a law enforcement was observed by millions of households via media at the onset of the issuance of social distancing orders by a legitimate authority. Social groups were formed to advocate for social change following the process of internalization and identification and social influences. Ineluctibly, social groups displayed public distrust of legitimate authority. The mobilization of interest groups worked collaboratively to organize protests and marches to demand equality and justice. The LGBTQ+ community and other minority-centered social groups participated in the efforts of the Black Lives Matter campaign to protest against police violence and to promote public policy. According to Medical University of South Carolina, public policy can be defined as, “... a system of laws, regulatory measures, courses of action, and funding priorities concerning a given topic promulgated by a governmental entity or its representatives" [5]. Social groups demanded justice for George Floyd and other black victims of police violence during the orientation of social orders of wearing masks and social distancing. Social protests persisted, sometimes violating those orders. During this time of ceaseless protests, a white police officer, Rustin Sheskey, shot an 
unarmed black man, Jacob Blake in Wisconsin. Social influence changes public behaviors of individuals in different ways. For example, heavily armed 17-year-old white male, Kyle Rittenhouse, killed two white protesters several days after the shooting of Jacob Blake. Many groups supported the 17-year-old because some supporters believed protests were in violation of social distance orders and were unorderly. Individuals or social groups demonstrating obedience to orders issued by an authority, will behave obediently even it means harming another person [4]. Social groups reached out to former vice president and president elect, Joe Biden, who proposed a $\$ 300$ million investment in community policing and funding would be provided to police departments. Also, Biden pledged to launch a national police oversight 'commission' by his 100th day in office. Other groups addressed former President Trump at various media briefings regarding police reform. On June 16, 2020, former President Donald Trump signed Executive Order No. 13929 in 2020 that included recommendations to enhance current grant programs to improve law enforcement practices and build community engagement, particularly, in African-American communities to swiftly address instances of misconduct. Also, the social group, National Association of Social Workers, helped to introduce the H.R. 7120 George Floyd in Policing Act of 2020 on June 25, 2020. The bill was introduced by social worker and California Representative, Karen Bass, who is also the Chair of the Congressional Black Caucus. The bill increases accountability of law enforcement to eliminate discriminatory policing practices, facilitates federal enforcement of constitutional violations and creates a national registry of complaints of police misconduct, referred to as, The National Police Misconduct Registry. The National Association of Social Workers proposed several ideas regarding police reform which includes: implementing police social work within police departments, providing implicit bias training that aims to increase fairness in officer decision making and expanding the 'Crisis Intervention Training Program' with focused attention on a community-based approach to improve the outcomes of police-involved encounters [9]. Legitimate authority, like Washtenaw County Sheriff's Office in Michigan, has focused on how they could change the agency culture first to promote a serviceoriented and community focused organization,"... in which trust of and with the community was foundational." Also, Mayor Tim Keller of Albuquerque, New Mexico plans to create a new community safety department that will use unarmed social workers, housing and homelessness specialists, and violence prevention coordinators to respond to nonemergency situations.

\section{RESULTS}

Social influences can be applied to conform social behaviors and individuals can change their behaviors or attitudes at any time. During the coronavirus pandemic, compliance, identification and internalization prompted four social influences: conformity, obedience, compliance and propaganda, which has been categorized as four intervals during coronavirus pandemic. Although psychological processes precipitates all four social influences, propaganda assists in the creation of social groups based on both normative conformity and informative conformity during a crisis. Normative and informative conformity become parallel to a legitimate authority due to the interposition of its social position amongst social groups. After a period of prolonged informative conformity and shorter period of normative conformity, a legitimate authority, who possesses the use of force, gives commands to social groups to promote two social influences: obedience and compliance. Thus, a legimate authority hijacks social influences from social groups, changing individual psychological processes and behaviors while interposing commands amid a crisis. Unquestionably, public policy becomes achievable due to an interposition of a legitimate authority enforcing two social influences: compliance and obedience towards rules or laws amongst social groups based normative and informative conformity subsequent propaganda.

\begin{tabular}{|r|c|c|c|}
\hline \multicolumn{5}{|c|}{$\begin{array}{r}\text { INTERPERSED SOCIAL INFLUENCES (SI) } \\
\text { (in intervals during COVID-19) }\end{array}$} \\
\hline \multicolumn{3}{|c|}{$\begin{array}{r}\text { Psychological Processes (PP) } \\
\text { Internalization, Compliance \& Identification }\end{array}$} & (SI4): Obedience \\
\hline \hline (SI1): Conformity & (SI2): Propaganda & (SI3): Compliance & Legitimate Authority (LA) \\
\hline Informative!Conformity (IC) & & Legitimate Authority (LA) \\
\hline $\begin{array}{c}\text { INTERVAL A } \\
\text { (PP), (SI1), (IC), (NC) }\end{array}$ & $\begin{array}{c}\text { INTERVAL B } \\
\text { (PP),(SI2),(IC),(NC) }\end{array}$ & $\begin{array}{c}\text { INTERVAL C } \\
\text { (PP),(SI3),(IC),(LA) }\end{array}$ & (PP),(SI4),(LA),(LA) \\
\hline
\end{tabular}




\section{DISCUSSION}

Interspersed social influence occurs when conformity, obedience, compliance and propaganda are applied in intervals during a crisis to manage anticipated social behaviors. Compliance, identification and internalization processes catalyzes the activity of social change. The propagation of public policy during the coronavirus crisis has been theoretically congruent to the process of obedience towards a legitimate authority in the context of demonstrating behaviors which are permissible courses of action within the law. Freedom of speech, protests, public policy legwork and the creation of propaganda are examples of actvities individuals may participate to incite social change, such as police reform, which has been a trending banner of social justice, subsequent the killing of George Floyd. Heretofore, the coronavirus crisis, public distrust of government and the interposition of a legitimate authority amongst social groups may have accelerated compliance and obedience as a social influence. Analogously, propaganda as a social influence was also accelerated to advance police reform or social change during normative and informative conformity amongst social groups.

\section{CONCLUSION}

Communication practitioners, communication professionals, and those who rely on strategic communications should understand the impact of social influences and interspersed social influences. Interspersed social influences are applied in intervals during a crisis to manage anticipated social behaviors. Although, social behaviors demonstrated through protests, freedom of speech, public policy formation and reform have been showcased many times before, the phenomena of cryptomnesia disaffirms aspects of social influence as a result of individual psychological processes but social influences are mostly manageable due to a predictability of social behaviors interposed by a legitimate authority. A legitimate authority determines acceptable social behaviors, such as protests, freedom of speech, public policy formation and reform, through a demonstration of use of force in response to social behaviors which are not acceptable. Conclusively, it is important to work in groups, perhaps working with a legitimate authority to strategically do the work of actual social change.

\section{Author Biography}

Alexia. L. Knox., B.A., M.P.A., M.A., is a Communications Comsultant, employee of the U.S. Census Bureau and alumni of Marquette University Graduate School of Management Diederich College of Communication, Milwaukee, WI 53202, USA; e-mail: alexia.knox@marquette.edu and alexia@lexincommunications.com ; ORCID: 0000-0002-9396-6685.

\section{REFERENCES}

[1] Altman, A. (2020, June 15). Why The Killing of George Floyd Sparked an American Uprising? Time. https://time.com/5847967/george-floyd-protests-trump

[2] Benkler, Y., Faris, R. \& Roberts, H. (2018). Network propaganda: Manipulation, Disinformation, and Radicalization in american politics. Oxford, UK: Oxford University.

[3] Dimock, M. (2020, February 19). How americans view trust, Facts, and Democracy today. Pew Research Center. Retrieved from https://www.pewtrusts.org/en/trust/archive/winter-2020/how-americans-view-trust-factsand-democracy-today

[4] Hammond, T. \& Jhangiani, R. (2014). Principles of social psychology. Influencing and Conformity ( $1^{\text {st }}$ Ed). Montreal. Canada: Press Books.

[5] Kilpatrick, D. (2000). Definitions of public policy and the law. Medical University of South Carolina.

[6] Pew Research Center. (2019, July 22). Key findings about Americans' declining trust in government and each other. [Report].

[7] Pew Research Center. (2020, September 14). Americans' views of government: Low trust, but Some positive prformance ratings. [Report].

[8] Pramuk, J. (2020, August 12). GOP, Dems share blame for unemployment benefits lapse, voters say in CNBC/Change poll. CNBC.

[9] Wilson, A. \& Wilson, M. (n.d.). Remaining policing: Strategies for community reinvestment pre-arrest diversion; and innovation approaches to 911 emergency responses. National Association of Social Workers. https://www.socialworkers.org/LinkClick.aspx?fileticket=GjXJr6rDzss\%3d\&portalid=0

[10] World Health Organization. (2020, March 18). Mental health and psychosocial considerations during the COVID-19 outbreak. https://www.who.int/docs/default-source/coronaviruse/mental-health-considerations.pdf. 